\title{
Research and Application of Health Monitoring System for Special-shaped Concrete-filled Steel Tube Arch Bridge
}

\author{
Xiaoqiang Ren ${ }^{1,2, a}$, Dapeng $\mathrm{Gu}^{3, b}$, Weiming Yan ${ }^{4, c}$, Yanjiang Chen ${ }^{5, \mathrm{~d}}$ \\ ${ }^{1,4,5}$ School of Architecture and Civil Engineering, Beijing University of Technology, \\ 100124, Beijing, China \\ ${ }^{2}$ Changchun Municipal Public Bureau, 130028, Changchun, China \\ ${ }^{3}$ Guodaotong Highway Design \& Research Institute CO., LTD, 100053, Beijing, China \\ arxqsir@vip.sina.com, 'bgudapeng2004@163.com (corresponding author), cyanwm@bjut.edu.cn, \\ dcyjrlx@sina.com
}

Keywords: Irregular shaped concrete-filled steel tube arch bridge, health monitoring system, system design.

Abstract. Bridge structural health monitoring system is very necessary to master operational condition, ensure safety of structure, detect damage and conduct effective maintenance. Based on the health monitoring system design of a irregular shaped concrete-filled steel tube arch bridge, this paper elaborates on the design principles of health monitoring system, and introduces the layout proposal of all kinds of sensors on the bridge and the matching collection system and software system. The practice may provide reference for the health monitoring system of long-span bridges.

\section{Introduction}

The bridge engineering accidents often took place in recent years in China, which caused significant casualties and property losses. People pay great attention to the safety of public transportation facilities. Timely decisions and early warning can prevent the further development of the injury, with the reasonable emergency treatment measures, when the bridge structure damage occurs. Those also can avoid the sudden destruction and other accidents especially. For the important bridge structure in service for a long time, if we conduct regular assessment correctly on the cumulative damage degree, the safety operation of bridge will be ensured with the technical state of structure which can be grasped fully and accordingly. In order to master the operational condition, ensure the safety of structure, found the damage and conduct the effective maintenance, it is very necessary to establish a bridge structure health monitoring system [1].

\section{Design Principles of Health Monitoring System}

In order to provide support for structural design, checking and correcting of model, damage identification, maintenance and repair, and the development of new technologies; the design of bridge health monitoring system needs to consider the health monitoring requirements of every stage of the engineering structure, characteristics, and the influence of environmental conditions changing comprehensively, with the combination of structure's specific characteristics and site conditions. The whole system should be secure and reliable, technologically- advanced, economical and reasonable, with the feasible proposal and easy maintenance [2].

According to the actual situation of a irregular shaped concrete-filled steel tube arch bridge, figure 1-1 gives design principles of the bridge. That means we should focus on practicality, taking into account the economy and stability, and advanced technological requirements, when we design the health monitoring system, with combination of norms of bridge design, construction, inspection and maintenance, carrying capacity assessment procedures and related standards [3,4]. 


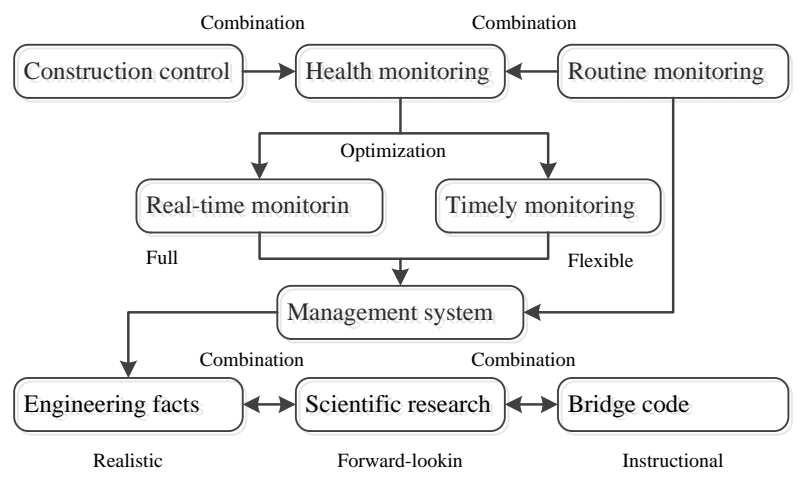

Fig. 1-1 Design principles of the bridge healthy monitoring system
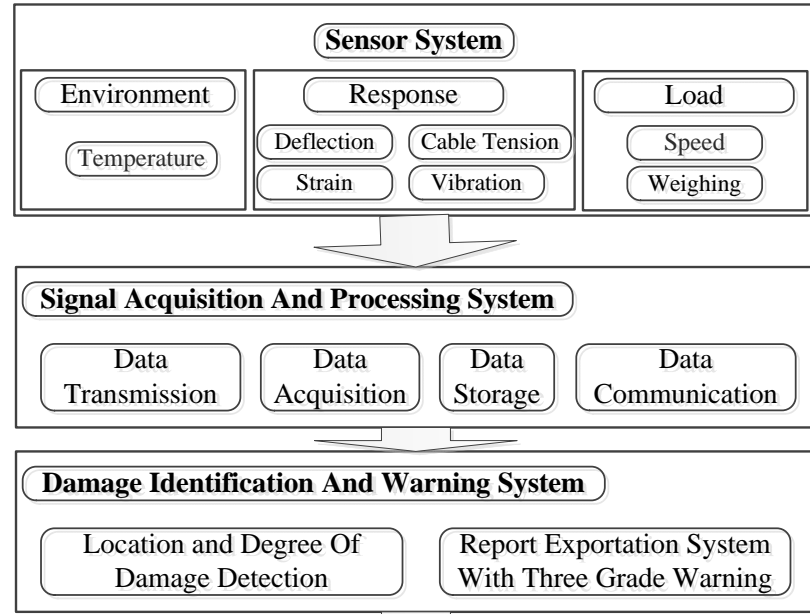

\begin{tabular}{|c|c|}
\hline Bridge Evaluation System & \\
\hline $\begin{array}{l}\text { Assessing Systems for Technical } \\
\text { State of Existing Bridges }\end{array}$ & $\begin{array}{l}\text { Assessment for Load Carrying } \\
\text { Capacity of Bridge Structures }\end{array}$ \\
\hline
\end{tabular}

Fig. 1-2 Components of the bridge healthy monitoring system

As can be seen from the above figure that the characteristic of health monitoring system of a irregular shaped concrete-filled steel tube arch bridge lies in:

(1) the combination of bridge health monitoring and construction monitoring.

(2) the combination of bridge health monitoring and bridge detection.

(3) the combination of real-time monitoring and timely monitoring.

(4) the combination of bridge health monitoring and bridge management system.

\section{Structure and Function of the Health Monitoring System}

Health monitoring system is mainly used with modern sensor technology, testing technology, computer technology and network communication technology to conduct the real-time monitoring and research for the working environment, traffic load and all kinds of response of the structure. To provide scientific basis of reliability assessment, operation management and maintenance, the study timely grasp the structural state and fully understand the operating conditions and performance degradation in the bridge[5]. The irregular shaped concrete-filled steel tube arch bridge health monitoring system mainly includes the sensor system, signal acquisition and processing system, damage identification and warning system, technology condition and safety assessment system, as shown in figure $1-2$.

The sensor system mainly includes fiber Bragg grating strain sensor, ultra-low frequency accelerometer of the 941B type, and QY inclinometer, thermocouple temperature sensor, dynamic weighbridge of piezoelectric thin film type, fiber Bragg grating cable tension sensor and the corresponding signal amplification device (see figure 1-3). This system mainly completes the measurement of the working environment, traffic load and static, dynamic response in the bridge operation state.

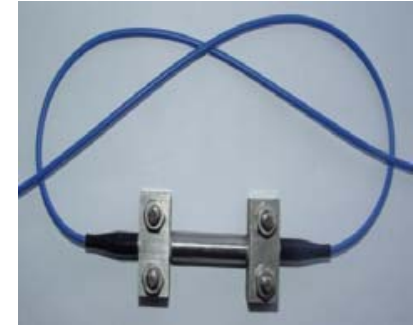

(a) fiber Bragg grating strain sensor

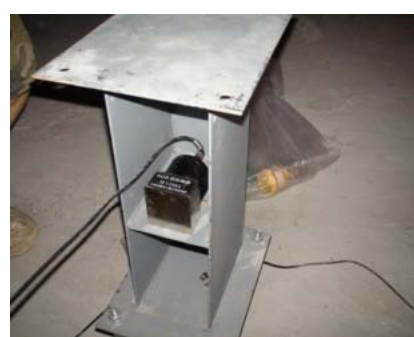

(b) 941B type ultra-low frequency accelerometer

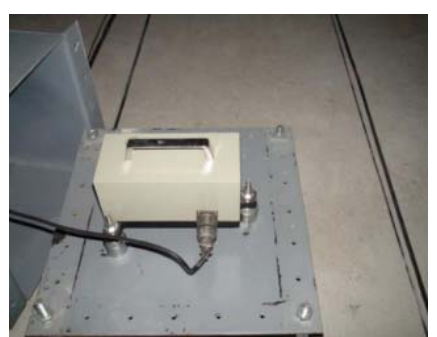

(c) QY inclinometer 


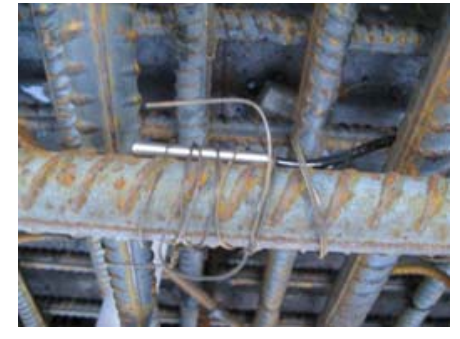

(a) fiber Bragg grating temperature sensor

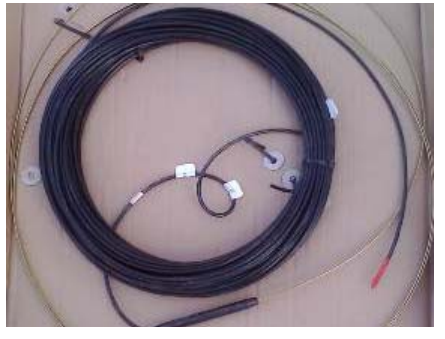

(b) piezoelectric thin film

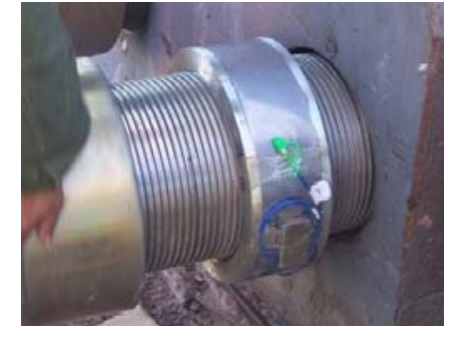

(c) fiber Bragg grating cable tension sensor

Fig. 1-3 Sensors types of the bridge healthy monitoring system

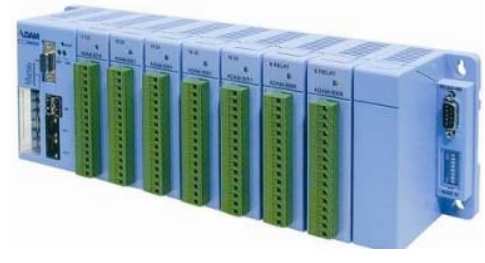

(a)electrical signal acquisition device
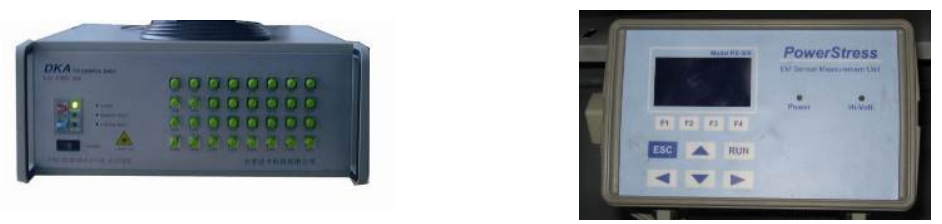

(b) optical signal acquisition device (c) electromagnetic signal acquisition device

Fig. 1-4 Acquisition device of the bridge healthy monitoring system

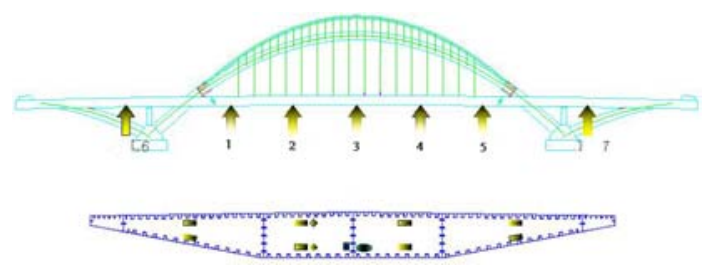

Fig. 1-5 Sensors arrangement on the cross section Fig. 1-6 Sensors arrangement on the cross section

The main three types of signal in sensors system include electrical signal, optical signal, and electromagnetic signal. The logic controller of ADAM-5550 type and ADAM-5017s high speed data acquisition card are used to collect the electrical signals (acceleration and inclinometer); Optical signals collected by fiber Bragg grating demodulator; Electromagnetic signal collected by magnetic elastic instrument, as shown in figure 1-4.

\section{Sensor System Arrangement}

Strain sensor should be arranged in the cross section with obvious stress (tension) state and the large change of strain, but at the same time the place should avoid beam position. Temperature field distribution in the cross section of the main girder adopts the one-to-one way for temperature compensation. Based on the results of the numerical analysis, the main girder is decorated 5 one-way acceleration sensors. In order to accurately monitor the static and dynamic deflection of bridge girder, the inclinometer will be arranged in the related position. The arrangements of measuring points are shown in figure 1-5. Strain and temperature sensor use the fiber Bragg grating strain sensor arrangement in the critical section. According to the calculation results of numerical analysis, the arch rib adopts bidirectional accelerometer (vertical and transverse). The specific point's position is shown in figure 1-6. The health monitoring system in this paper uses the fiber Bragg grating cable tension meter, with integrating requirements of precision, linearity and durability. There are a total of 16 fibers Bragg grating cable tension meters in the bridge, as shown in figure 1-7. 


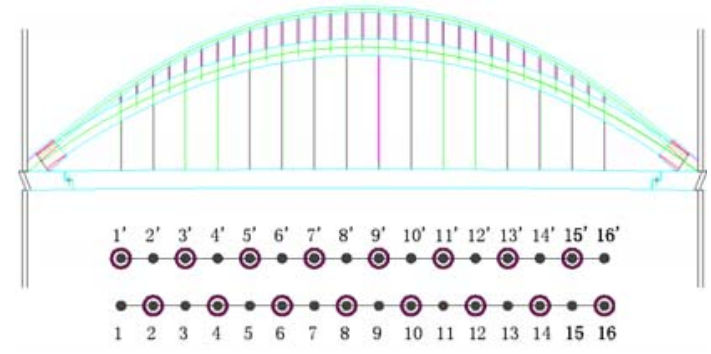

Fig.1-7 Sensors arrangement on the cross section

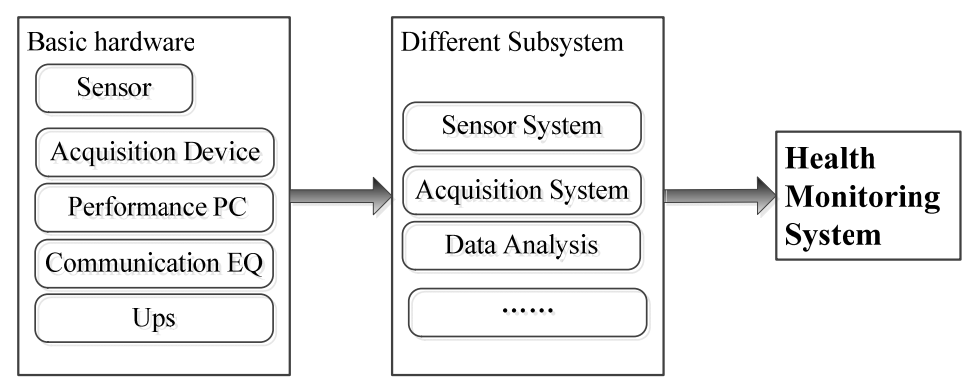

Fig.1-8 Modular design of the health monitoring system

\section{Health Monitoring System Software Design}

The special-shaped concrete-filled steel tube arch bridge health monitoring software design mainly involves two aspects: local monitoring processing and remote client access. Local monitoring of the project achieve the following four basic functions: the original data collection, data storage, data display, and data services. Remote client project depend on data provided by the server (raw data and results data), to achieve the function of monitoring personnel remote login data.

Different instruments are integrated organically in bridge health monitoring system, such as sensors, collecting instrument, high-performance computer, routers and switches, with assembled into a specific function of the subsystem. Then the subsystem are combined again and finally form the health monitoring system, as shown in figure 1-8 as follows.

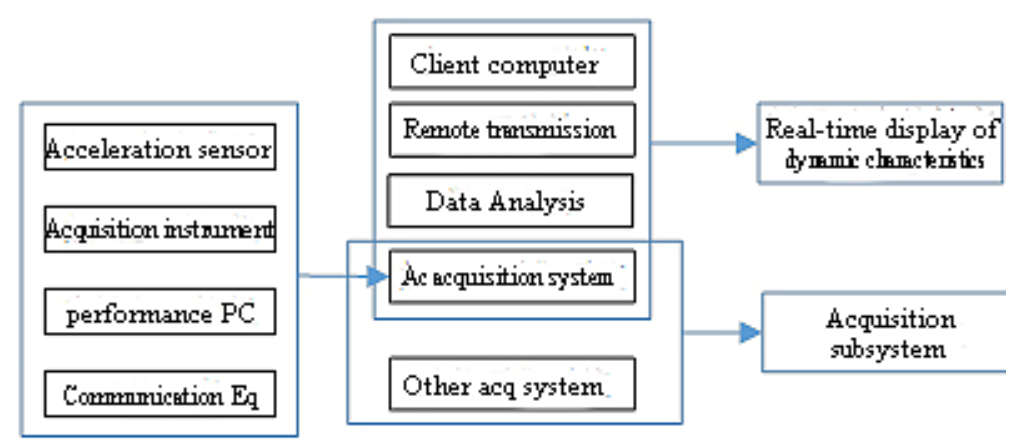

Fig.1-9 The combination between different modules and acceleration acquisition system

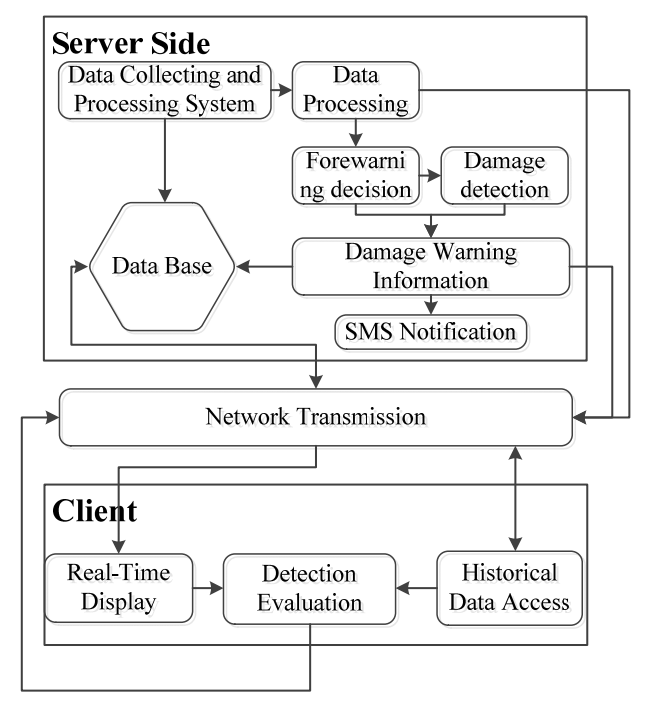

Fig.1-10 software-architecture for the bridge health monitoring system

Acceleration sensor and its acquisition equipment, high-performance computer, and some communication equipment such as shielding wire, cable, switch, etc., can be composed of acceleration data acquisition system. Adding the acceleration analysis module (modal identification) and remote transmission subsystem, the system can realize remote display on the acceleration data; Other types of monitoring data acquisition system can be implemented in the same way. Different types of acquisition system consist of data acquisition system, as shown in figure 1-9. Health monitoring system is the organic combination of different modules or subsystems, which is implemented by software. Based on the Net framework 4.0 platform and windows 7 operating system, the irregular shaped concrete-filled steel tube arch bridge's health monitoring system is implemented by using the modern programming techniques: WPF (Windows Presentation Foundation) technology, MVVM (Model - View - the View Model) design pattern, Code First development pattern, the SMO (SQL Server Management Objects) technology, with Microsoft Visual Studio 2010 and Microsoft SQL Server 2012 database as a tool for system development. Clearing monitoring data processing 
procedure is the most important parts in the health monitoring software, and the specific software architecture are shown in figure 1-10 below.

\section{Summary}

This paper is based on the engineering background of a irregular shaped concrete-filled steel tube arch bridge health monitoring system, and research on the construction of concrete-filled steel tube arch bridge health monitoring system. This scientific and reasonable health monitoring system is mainly constructed upon the inherent characteristics and the specific structure of concrete filled steel tube arch bridge. This paper introduces the system of monitoring content, composition and the function of bridge health monitoring software system in detail, to provide a reference for the future construction of concrete-filled steel tube arch bridge health monitoring system.

\section{References}

[1] Li Hui, Zhou Wensong, Ou Jinping, Yang Yongshun. A study on system integration technique of intelligent monitoring systems for soundness of long-span bridges. China Civil Engineering Journal 2006(02): 46-52.

[2] Charles R. Farrar, Hoon Sohn. Condition and Damage Monitoring Methodologies. Invited Talk, The Consortium of Organizations for Strong Motion Observation Systems (COSMOS) Worksh, Emeryville, CA November 14-15, 2001, LA-UR-01-6573.

[3] Housner G. W., Bergman L. A., Caughey T. K. et al. Structural Control: Past, Present, and Future. Journal of Engineering Mechanics. 1997, 123(9):897 971

[4] Li Xianghui. Research on health monitoring for medium and small span prestressed concrete bridge[D]. Jilin University, 2011.

[5] LI Hong nan, LI Dong sheng. Safety assessment, health monitoring and damage diagnosis for structures in civil engineering. Earthquake Engineering and Engineering Vibration. 2002, 22(3):82 90 